\title{
Evaluation of Incidence of Post-Dural Puncture Headache with Maintenance of Sitting Position Immediately After Spinal Anesthesia
}

\author{
Kyu Chang Lee, Dae-Jeong Koo, Won Sang Lee, Hye Young Kim, Yusun Choi, Myeong Jong Lee* \\ Department of Anesthesiology and Pain Medicine, Konkuk University Medical School, Chungju, Korea \\ Email address: \\ gooddr21@naver.com (M. J. Lee) \\ To cite this article: \\ Kyu Chang Lee, Dae-Jeong Koo, Won Sang Lee, Hye Young Kim, Yusun Choi, Myeong Jong Lee. Evaluation of Incidence of Post-Dural \\ Puncture Headache with Maintenance of Sitting Position Immediately After Spinal Anesthesia. Journal of Anesthesiology. \\ Vol. 3, No. 4, 2015, pp. 14-16. doi: 10.11648/j.ja.20150304.11
}

\begin{abstract}
Background: In spinal saddle anesthesia, maintaining the sitting position for 3-5 min, to allow for the descent of the injected drug after lumbar dural puncture, minimizes side effects such as blood pressure reduction. However, it also increases cerebrospinal fluid leakage due to the hydrostatic pressure. We investigated the effects of the maintenance of the sitting position after spinal anesthesia on the development of postdural puncture headache (PDPH). Methods: We reviewed all data of patients undergoing spinal anesthesia performed between January 1, 2012 and December 31, 2013 retrospectively. The incidence of PDPH and epidural blood patch administration were investigated after grouping patients into two groups: the SP group (patients were laid down immediately after spinal anesthesia) and the SA group (patients were maintained in the sitting position for 3-5 min before changing to the operating position). Results: There were no cases of severe PDPH or epidural blood patch administration in the SP group. In the SA group, there were four cases (4\%) of PDPH, and among these, three cases $(3 \%)$ required epidural blood patch administration. Conclusions: The maintenance of the sitting position after spinal anesthesia caused a persistent increase in the transdural pressure, resulting in a higher incidence of PDPH compared with patients that were laid down immediately after anesthesia.
\end{abstract}

Keywords: CSF Leakage, Epidural Blood Patch, Hydrostatic Pressure, Postdural Puncture Headache, Saddle Anesthesia, Sitting Position

\section{Introduction}

For surgery in the perianal area or perineal area, caudal anesthesia or saddle anesthesia are the most frequently performed types of anesthesia due to their sufficient blocking at the sacral dermatome level. However, caudal anesthesia requires a large administration of local anesthetic drugs and the status of the anesthesia is unclear in many cases due to numerous anatomical variations and the large epidural space of the caudal area [1-3]. Therefore, saddle anesthesia is performed in many cases; a hyperbaric drug is injected in the sitting position after lumbar dural puncture and the sitting position is maintained for $3-5 \mathrm{~min}$ to allow the drug to descend, consequently only blocking the sacral dermatome. There are a few complications associated with saddle anesthesia, these are related to an increase in the anesthesia level and other hemodynamic issues, among which, the development of postdural puncture headache (PDPH) is the largest complication $[1,4,5]$. Few studies have investigated the relationship between the duration of the maintenance of the sitting position post-anesthesia drug injection and the development of PDPH. Therefore, we investigated the effects of the time-dependent pressure change in the subarachnoid space or epidural space on the development of PDPH, by maintaining the sitting position for 3-5 min post-spinal anesthesia.

\section{Materials and Methods}

All patients undergoing spinal anesthesia at this hospital between January 1, 2012 and December 31, 2013 were eligible in this study. The study protocol and data collection was approved by the hospital's institutional review board. The incidence of PDPH and epidural blood patch administration was retrospectively investigated after grouping patients into either a SP group (patients were laid 
down immediately after spinal anesthesia) or a SA group (patients were maintained in the sitting position for 3-5 min before changing to the operating position).

Upon entering the operating room, the patient was laid on the operating table and vital signs and peripheral capillary oxygen saturation were measured. After adoption of the sitting or lateral decubitus position, dural puncture at the L4 L5 or L3-L4 level was performed with a 23- or 25-gauge Quincke needle, after skin disinfection and coating. There were no cases in which puncture was performed more than twice. If a patient complained of PDPH after surgery, symptomatic therapies such as hydration, abdominal binders, and caffeine administration were performed. If the patient did not respond to these therapies, due to severe PDPH, an epidural blood patch was administered.

\section{Results}

There were no statistically significant differences in age, sex, height, weight, and American Society of Anesthesiologists physical status between the SP and SA groups; however, there were statistically significant differences in operation and anesthesia duration, and distribution of operating departments (Table 1).

Table 1. Demographic Data.

\begin{tabular}{llll}
\hline & SP group $(\mathbf{n}=221)$ & SA group $(\mathbf{n = 1 0 1})$ & P \\
\hline Age (years) & $56.7 \pm 15.2$ & $53.6 \pm 15.4$ & 0.110 \\
Sex (M/F) & $146 / 75$ & $66 / 35$ & 0.498 \\
$\begin{array}{l}\text { Height (cm) } \\
\text { Weight (kg) }\end{array}$ & $163.5 \pm 9.7$ & $163.4 \pm 8.8$ & 0.715 \\
$\begin{array}{l}\text { ASA physical status } \\
\text { ( I / II / III) }\end{array}$ & $71.0 \pm 17.2$ & $65.3 \pm 13.4$ & 0.089 \\
$\begin{array}{l}\text { Duration of } \\
\text { operation (min) }\end{array}$ & $41.9 \pm 33.3$ & $54 / 36 / 11$ & 0.062 \\
$\begin{array}{l}\text { Duration of } \\
\text { anesthesia (min) }\end{array}$ & $74.9 \pm 38.0$ & $17.9 \pm 11.4$ & 0.000 \\
GS/URO/OS/OB/PS & $14 / 141 / 55 / 6 / 5$ & $48.6 \pm 13.5$ & 0.000 \\
\hline
\end{tabular}

Values are mean $\pm \mathrm{SD}$ or number of patients. $\mathrm{P}$ values are compared with group SP and SA.

Table 2. Factors of Spinal Anesthesia.

\begin{tabular}{|c|c|c|c|}
\hline & $\begin{array}{l}\text { SP group } \\
(\mathrm{n}=221)\end{array}$ & $\begin{array}{l}\text { SA group } \\
(\mathrm{n}=101)\end{array}$ & $\mathbf{P}$ \\
\hline Size of needle(23G/25G) & $173 / 48$ & $26 / 75$ & 0.000 \\
\hline Dose of bupivacaine (mg) & $7.7 \pm 1.8$ & $4.7 \pm 0.8$ & 0.000 \\
\hline $\begin{array}{l}\text { Epinephrine with bupivacaine } \\
\text { (Yes/No) }\end{array}$ & $175 / 46$ & $16 / 85$ & 0.000 \\
\hline Sensory level of spinal anesthesia & $\mathrm{T} 10.4 \pm 2.4$ & $\mathrm{~L} 4.9 \pm 2.3$ & 0.000 \\
\hline $\begin{array}{l}\text { Requirement of vasopressor } \\
\text { (Ephedrine or Phenylephrine) }\end{array}$ & $22(10.0)$ & $5(5.0)$ & 0.096 \\
\hline Volume of fluid (mL) & $\begin{array}{l}575.6 \\
281.6\end{array}$ & $\begin{array}{l}392.0 \\
224.0\end{array}$ & 0.000 \\
\hline
\end{tabular}

Values are mean \pm SD or number of patients (\%). P values are compared with group SP and SA.

Statistically significant differences in needle size, bupivacaine dose, anesthetic level, and injected liquid volume during anesthesia were recorded between the two groups. While the frequency of pressor agent (ephedrine or phenylephrine) utilization was higher in the SP group, there were no statistically significant differences between the two groups (Table 2).

There were no cases of severe PDPH or epidural blood patch administration in the SP group; however, there were four cases (4\%) of PDPH in the SA group, among these, three cases $(3 \%)$ required an epidural blood patch (Table 3 ).

Table 3. Incidence of Postdural Puncture headache (PDPH) and Epidural Blood Patch.

\begin{tabular}{llll}
\hline & SP group $(\mathbf{n}=\mathbf{2 2 1})$ & SA group $(\mathbf{n}=\mathbf{1 0 1})$ & $\mathbf{P}$ \\
\hline PDPH & $0(0)$ & $4(4.0)$ & 0.009 \\
$\begin{array}{l}\text { Epidural blood } \\
\text { patch }\end{array}$ & $0(0)$ & $3(3.0)$ & 0.030 \\
\hline
\end{tabular}

Values are numbers (\%). P values are compared with group SP and SA.

\section{Discussion}

PDPH is a complication of postdural puncture, where the sitting position cannot be adopted due to unbearable headache, forcing the patient to lie down [6]. In these cases, symptomatic therapies such as hydration, abdominal binders, and caffeine administration can be performed, while an epidural blood patch is administered for severe cases of PDPH that do not respond to symptomatic therapies [7]. PDPH is caused by the stimulation of the pain sensitive vascular structure at the base of the brain following a reduction in cerebrospinal fluid (CSF) pressure, caused by the continuous leakage of CSF into the epidural space due to epidural puncture [8]. Therefore, the greater the amount of CSF leakage volume, the lower the CSF pressure and the higher risk of PDPH.

The CSF leakage volume is proportional to the transdural pressure between the subarachnoid space and epidural space, and the leakage duration. It is also inversely proportional to the resistance loaded in the hole created by a puncture in the arachnoid membrane and dura mater (modified Ohm's Law). Furthermore, the resistance is proportional to the puncture hole length and CSF viscosity, and inversely proportional to the fourth power of the radius of the puncture hole. To reduce the incidence of PDPH, the CSF leakage volume has to be minimized. Methods to reduce the leakage volume include those that supplement the CSF volume, reduce the subarachnoid space pressure, increase epidural space pressure, reduce puncture hole radius, increase CSF viscosity, and those that reduce CSF leakage duration. We predicted that, due to the maintenance of the sitting position for 3-5 minutes post-anesthetic drug administration, the CSF hydrostatic pressure would be greater in the SA group than in the SP group (that immediately changed to the horizontal position), resulting in elevated CSF leakage and a greater incidence of PDPH.

After performing an animal experiment, Kuzman et al. reported that the lumbar subarachnoid space pressure in horizontal and vertical positions was $17.8 \pm 1.2 \mathrm{cmH} 2 \mathrm{O}$ and $33.5 \pm 2.3 \mathrm{cmH} 2 \mathrm{O}$, respectively [2]. Shah confirmed an 
epidural pressure of $6.4 \mathrm{cmH} 2 \mathrm{O}$ (range $0.5-12 \mathrm{~cm} \mathrm{H} 2 \mathrm{O}$ ) in PDPH patients and reported a reduction in epidural pressure at dural puncture from $14.9 \mathrm{cmH} 2 \mathrm{O}$ (range $11-22 \mathrm{~cm} \mathrm{H} 2 \mathrm{O}$ ) to $6.9 \mathrm{cmH} 2 \mathrm{O}$ (range $5.0-8.5 \mathrm{cmH} 2 \mathrm{O}$ ) [3]. This suggests that the supine position is effective at preventing PDPH by reducing the pressure in the subarachnoid space. There has been no association recorded between the post-operative duration of lying in the supine position and PDPH incidence in spinal anesthesia patients $[1,4,5]$. In addition, Tejavanija et al. reported that there was no difference in PDPH incidence between early ambulation and lying for 6-h postoperatively in patients who received spinal anesthesia [9].

A review of the literature revealed only one published randomized controlled trial comparing the influence of sitting position duration and PDPH incidence [10]. Schmittner et al. investigated PDPH incidence by randomizing anorectal surgery patients into two groups: those that maintained the sitting position for $10 \mathrm{~min}$ and those that maintained the sitting position for $30 \mathrm{~min}$ [10]. There were no statistically significant differences reported between the two groups. However, this study did not include a control group, in which patients were laid down immediately; more reliable evidence for the relationship between position and PDPH incidence may have been obtained if a control group was included.

In this study, while there was no incidence of PDPH or epidural blood patch administration in the SP group, in the SA group there were four cases (4\%) of PDPH, and among these, three cases $(3 \%)$ required an epidural blood patch. Since epidural repair was performed only in the SA group, an increase in CSF leakage or damage in the epidural puncture area, caused by the pressure difference between the inside and outside of the dura mater during that time, can be inferred.

Limitations of the current study are mostly from retrospective record review, i. e. nonrandomized design. First, the duration for which SA group was retained was 3-5 minutes. It could be argued that patients kept sitting for 3 minutes would have less incidence and severity of PDPH as compared to those who were made to sit upright for 5 minutes, since the former would lose less CSF. Second, incidence of adding epinephrine to bupivacaine in two group was $79 \%$ (SP group) and $16 \%$ (SA group) respectively (Table 2), which coud have been a confounding factor.

In conclusions, these findings indicate that the maintenance of the sitting position immediately after epidural puncture may critically affect the incidence of PDPH. However, it is necessary to obtain more advanced results through scientific pressure measurements, dependent on the position, from in vivo animal experiments and PDPH correlation studies and further well-designed randomized controlled research into this correlation is clearly warranted based on the current study findings.

\section{References}

[1] Butterworth JF, Mackey DC, Wasnick JD. Morgan \& Mikhail's Clinical anesthesiology. $5^{\text {th }}$ ed. New York, McGrawHill Companies, Inc. 2013, pp 969-70.

[2] Kuzman T, Jurjević I, Mandac I, Radoš M, Orešković D, Jednačak $\mathrm{H}$, et al. The effect of body position on intraocular and CSF pressures in the lateral ventricle, and in cortical and lumbar subarachnoid spaces in cats. Acta Neurochir Suppl 2012; 114: 357-61.

[3] Shah JL. Epidural pressure and postdural puncture headache in the parturient. Int J Obstet Anesth 1993; 2: 187-9.

[4] Miller RD, Eriksson LI, Fleisher LA, Wiener-Krenish JP, Young WL. Miller's Anesthesia. $7^{\text {th }}$ ed. Philadelphia, Churchill Livingstone.2010, pp 1626-7.

[5] Barash PG, Cullen BF, Stoelting RK, Cahalan MK, Stock MC Clinical anesthesia. $6^{\text {th }}$ ed. Philadelphia, Lippincott. 2009, 583-4.

[6] Lybecker H, Djernes M, Schmidt TF. Postdural puncture headache (PDPH): Onset, duration, severity, and associated symptoms An analysis of 75 consecutive patients with PDPH. Acta Anaesthesiol Scand 1995; 39: 605-12.

[7] Jones RJ. The role of recumbency in the prevention and treatment of postspinal headache. Anesth Analg 1974; 53: 788-796.

[8] Carbaat PA, van Crevel H. Lumbar puncture headache: controlled study on the preventive effect of 24 hours' bed rest. Lancet 1981; 2: 1133-1135.

[9] Tejavanija S, Sithinamsuwan P, Sithinamsuwan N, Nidhinandana S, Suwantamee J. Comparison of prevalence of post-dural puncture headache between six hour-supine recumbence and early ambulation after lumbar puncture in thai patients: A randomized controlled study. J Med Assoc Thai 2006; 89: 814-20.

[10] Schmittner MD, Urban N, Janke A, Weiss C, Bussen DG, Burmeister MA et al. Influence of the pre-operative time in upright sitting position and the needle type on the incidence of post-dural puncture headache (PDPH) in patients receiving a spinal saddle block for anorectal surgery. Int J Colorectal Dis 2011; 26: 97-102. 